\title{
The challenge for medicine
}

\author{
Deirdre Cunningham
}

Deirdre Cunningham FFPHM, Director of Public Health and Health Systems, Lambeth

Southwark and Lewisham Health Authority

Clin Med JRCPL 2001;1:194-6
Abstract - The biggest challenge for clinicians is their relationship with patients and the public. As knowledge and technical possibilities have advanced, there is evidence that the healthcare system is falling down in the more mundane aspects of healthcare. What has gone wrong with healthcare? Four published case studies are discussed.

The government and the General Medical Council are determined to put the patient at the centre of healthcare. Examples of what this means are given from the NHS Plan, the Duties of a Doctor and recommendations from a Leeds Castle healthcare symposium.

The changes involved are articulated from clinicians' perspectives and the patient perspective draws on recent publications documenting three (journalist) patients' experiences.

Professionals will have to be trained more with the patient in mind. Allegiances will be to patients and teams rather than institutions and teams must be clearly accountable. We are ready.

The biggest challenge for clinicians today is their relationship with patients and the public. Clinicians have become more scientific and technical in their practice, but according to the media their relationship with patients and the public has deteriorated. Most failures have complex causes and are largely a product of the system, but frequently clinicians take sole blame. In the media the NHS and clinicians have been pictured as capable of extraordinary inhumanity, yet the NHS is there to serve the public and patients. Dissatisfaction amongst patients has made it possible for private health care to exist. Patients must be at the centre of what we do, including research. This will involve change. Are we up to it?

\section{The advance of science and technology}

During the last century technology in the West has made rapid advances. Surgeons can now transplant organs routinely. The pharmacological revolution has produced drugs to stop rejection. We can now control infection with antibiotics (used wisely). We can assist conception and give low birthweight babies a chance to survive. Mapping the human genome and biotechnology could help us dramatically to improve human health and happiness. It depends on how we use these developments, and on whether such developments seduce us into ignoring patients' and peoples' basic health and health care needs.

Knowledge, which used to be held - often relatively secretly - by professionals, is now more freely available. Developments in communication technology can be compared with the changes of the industrial revolution ${ }^{1}$. Patient empowerment through the Internet has raised new possibilities. Knowledge is no longer restricted to professionals. Clinicians have privileged access to such sites as Doctors.net but then so have patients. They can receive information - and marketing - from anywhere in the world. Much of the professional's role should arguably be in interpreting that knowledge and using these skills for the patient's benefit. Research cannot be a Holy Grail pursued at the expense of the patient.

\section{What's gone wrong with our relationship?}

Most clinicians are likely to be conscientious, highly motivated and feel that they have the patients' interests at heart. That may be true, but no-one can be perfect all of the time. Recent media stories must cause concern to patients, the public and the profession. They portray seemingly isolated events at whose roots we find the same systematic problems. The Bristol Paediatric Cardiac Surgery Enquiry uncovered a dysfunctional relationship between hospital, patients and families, and between clinicians and management. At Alder Hey there appeared to be a cultural mismatch between patients' or families' views and those of clinicians and academics. The appropriate discussions had never taken place.

Where the health care system mostly falls down is in the more mundane aspects of care. What's gone wrong with health care ${ }^{2}$ According to a report from the King's Fund, patients who needed human understanding did not get it. Why? They were not listened to; clinicians did not communicate with each other, or with the patients or families. The goals pursued by the clinicians were different from those of the patients concerned. High-tech medicine was delivered, low-tech care was desired. The system had failed these patients. If these stories are typical they suggest that there is a lot we could do to make care 
patient-centred. And it would not all involve doing more; less in fact. But communicating more; working more in partnership.

\section{The NHS is guilty of inhumanity}

Three examples from five case studies illustrate how the best of intentions can result in inhumanity.

A 57 year old woman whose bowel symptoms were treated conservatively by her GP after excluding pathology. He saw her symptoms as a reflection of her unhappiness. Three years later her condition was treated aggressively by a locum to eradicate Helicobacter. She developed complications, was treated more and more heroically, developed multi-organ failure, was kept on life support and eventually died.

A Catholic priest, who had spent his whole life preparing for a good death, suffered a series of health events. Despite his wish for a peaceful end, his last illness, a heart attack with congestive cardiac failure, was treated against his wishes in a hospital where every technical intervention possible was used to prolong his life. His end was anything but peaceful.

A 70 year old woman, being treated in hospital, was unaware what her treatment was for, and unwilling to be a burden on the health care workers. She was discharged home despite the failure of her transport to arrive. No clear discharge plan had been made, and eventually she was referred to a day hospital which she attended uncomplainingly, still having no idea what was wrong with her.

These three scenarios can be seen as system failures - and we know that most adverse events are products of the local culture and the system, rather than any one individual ${ }^{3}$. But it is clinicians who frequently bear the brunt of public and media criticism. So we as clinicians need to take initiative to change this perception.

\section{The NHS and health care are for patients and the public}

We are all patients from time to time. We would all like to take it for granted that our health care should respect our views and be tailored to our wishes, our culture, our expectations. We should be asked what those are. This is also the national view. 'The NHS is for patients and needs to modernise to meet the demands of the public', said the Prime Minister ${ }^{4}$.

Three recent government publications particularly have put patients at the centre. Most physicians will have heard of patient-public partnership (PPP) strategies, but possibly not the NHS Patient Partnership Strategy (PPS $)^{5}$. The Patient and Public Involvement in the New NHS (PPI $)^{6}$ is is perhaps the least well-known because it was the 210th Government circular issued in 1999. Then in 2000 the Government issued the NHS Plan $^{7}$. College Presidents and others signed up to the ten core principles of the NHS; the third of these states that 'the NHS will shape its services around the needs and preferences of individual patients, their families and carers.' The NHS plan acknowledges that 'patients are the most important people in the health service' and that 'it doesn't always appear that way'.

\begin{tabular}{ll}
$\begin{array}{l}\text { Box 1 } \\
\text { NHS plan }\end{array}$ & Patient and public involvement \\
\hline $\begin{array}{l}\text { Information to empower } \\
\text { patients }\end{array}$ & $\begin{array}{l}\text { Patient involvement is a way all } \\
\text { organisations work } \\
\text { Strengthening patient choice }\end{array}$ \\
$\begin{array}{l}\text { Individual patient-clinician } \\
\text { relationship crucial } \\
\text { Growing acceptance that patients, }\end{array}$ \\
Patient advocacy service & $\begin{array}{l}\text { Involving users and carers } \\
\text { important to NHS quality }\end{array}$ \\
Rights of redress & $\begin{array}{l}\text { Patients involved in clinical } \\
\text { governance }\end{array}$ \\
Patients' views & $\begin{array}{l}\text { National involvement of patients } \\
\text { eg NICE*, NSFs } \\
\text { Local involvement expected }\end{array}$ \\
Scrutiny of the NHS & $\begin{array}{l}\text { Particular efforts to be made to } \\
\text { include BME patients }\end{array}$ \\
$\begin{array}{l}\text { Patients represented } \\
\text { throughout the NHS }\end{array}$ &
\end{tabular}

(*NICE - National Institute for Clinical Excellence)

The General Medical Council also places the patient at the centre in its Duties of a doctor ${ }^{8}$.

\section{Patients must be at the centre}

What does putting them at the centre actually mean? It means better alignment of what most patients need with clinicians' interests, research and practice. For instance, many patients suffer from chronic disease, for which there is no miraculous cure. 'Better ways to manage chronic disease have been known for years, but those ways have been neglected at policy and institutional levels. The longer the neglect the more distant effective and efficient healthcare will be. The bedrock of the better ways is a partnership between patients and physicians'9.

It also means coming to terms with the fact that cure is not the only acceptable goal. 'Not to be able to give patients a pill or an operation and send them on their way with a cure, goes against what we have come to expect of modern medicine ${ }^{10}$.

There are differing perceptions of what 'putting patients at the centre' means, and some of them are documented here:

The GMC's views of what it means are embodied in Duties of a doctor. Extracts of the duties of care include:

First duty of care: You must take suitable and prompt action when necessary;

Second duty of care: To establish and maintain trust you must listen to patients and respect their views - respect the right of patients to be fully involved in decisions about their care etc;

Third duty of care: You must not allow your view about a patient's lifestyle, culture, beliefs, race, colour, sex, sexuality, age, social status, or perceived economic worth to prejudice the treatment you give or arrange.

Indeed there is an acceptance that the doctor-patient relationship needs to be redefined as a partnership where the health professional acts as an adviser and leaves it to the patient to 


\begin{tabular}{ll}
$\begin{array}{l}\text { Box } 2 \\
\text { Leeds Castle recommendations }\end{array}$ & Specific proposals \\
\hline Empowering patients & Patient held records \\
Supporting choice & Key workers, care plans \\
Extending knowledge & Training and public education \\
Improving communication & $\begin{array}{l}\text { Teamwork and skilled } \\
\text { leadership }\end{array}$ \\
Delivering teamwork & $\begin{array}{l}\text { Finding ways of } \\
\text { communicating risk to patients }\end{array}$ \\
Encouraging autonomy & Multi-professional training
\end{tabular}

determine what should be done after receiving full information $^{11}$. There is an increasing need to respect the autonomy of patients $^{12}$.

Box 2 lists some of the recommendations put forward by a Leeds Castle Foundation Medical Conference in the Autumn of 1999 to improve the UK health care system.

Other reasons for emphasising patients include survival and consumerist or even commercial interests. Medicine will have to become 'patient centred'. 'Responding responsibly to this challenge is the greatest challenge facing the medical profession as it advances into the new millennium ${ }^{8}$.

In the future there will be more and more varieties of medicine. It will be revolutionised by electronic communications, and may come to be seen as the pursuit of ideal states of body or mind (the medical nirvana or beauty parlour, available commercially) or increasingly considering entitlements and rationing.

\section{The changes involved}

What does this mean for clinicians? That may be what many, even most, clinicians do already, on their good days. But that is no longer enough. They have to become more consistent and more explicit in putting patients at the centre. It will need a wholehearted approach to rise to the occasion. First they must want to involve patients more. For that to happen they must see the purpose and understand how there could be benefits, both to patients and to themselves. They will have to be prepared to put in the time and effort to understand how they're affecting patients and how things could be improved. What do patients want from the system, what do they not want? There may not be much time to spare at the moment, but if we stop doing some of those things patients don't actually want, more time might be available.

Many recent publications by articulate patients or their relatives (often journalists) document the progress of their illnesses, and how clinicians and the system coped. Their feelings, and a sense of disempowerment which such illnesses bring, are illuminating. Examples include one relatively young man's experience of a stroke ${ }^{13}$, and two people's experience of cancer ${ }^{14,15}$. But these are the younger, more articulate patients, whose first language is English. Would you be as familiar with what people from different cultures and educational back- grounds without English as a first language might want or experience? (Maybe we're valuing scientific aptitude more than humanity in the selection and training processes of medical education). Professionals will have to be trained more with patients in mind. They will be required to communicate well, with each other, with families, carers and patients and across the system. We will also have to have allegiances to clinical networks and teams caring for people both in the community and in hospital, rather than have allegiances to hospitals and institutions. The concept of teamwork can be confusing, and accountability for teams unclear ${ }^{12}$. They may result in no-one knowing the full picture, no-one accepting that they are in charge. Roles may be confused, training and professional development haphazard. This is a risk for individual professional members when they are dysfunctional. It is a risk for patients and system failure too. How can we support young doctors to work in teams? Generally we need to be a bit more human. It will mean recognising that we ourselves are not perfect, and making allowances for that.

It will need courage not to be threatened by the proposed changes but to embrace them.

\section{Are we up to it?}

Yes.

\section{References}

1 Aaronovitch D. Logging on to the new world order. Independent, 8 March 2000.

2 Hill A (Ed). What's gone wrong with health care? Challenges for the new millennium. London: King's Fund, 2000.

3 Porter R. Millennial musings. Br Med J 2000;321:1092-3.

4 Department of Health. The new NHS: modern, dependable. London: The Stationery Office, 1997.

5 NHS Executive. Patient partnership: building a collaborative strategy. Leeds: NHS Executive Quality and Consumers Branch, 1996.

6 NHS Executive. Patient and public involvement in the new NHS. London: Department of Health, 1999. HSC 1999/2000.

7 Department of Health. The NHS plan. London: The Stationery Office, 2000.

8 General Medical Council. The duties of a doctor. London: General Medical Council, 1995.

9 Holman H, Lorig K. Patients as partners in managing chronic disease. Br Med J 2000;320: 526-7.

10 McCrum R. Dark side of the brain - medics ill-equipped for stroke. BMA News Review, March 2000.

11 General Medical Council. Seeking patients' consent: the ethical considerations. London: General Medical Council, 1999.

12 Chantler C. Professional issues. In: Hill A (Ed.) What's gone wrong with health care? Challenges for the new millennium. London: King's Fund, 2000 .

13 McCrum R. My year off. London: Picador, 1998.

14 Diamond J. Because cowards get cancer too. London: Picador, 1998.

15 Arthur L, Arthur T. Shadow in tiger country. London: Harper Collins, 2000 .

Address for correspondence: Dr Deirdre Cunningham, Lambeth Southwark \& Lewisham Health Authority,

1 Lower Marsh, London SE1 7NT 